\title{
Evaluation of the effect of variable compression ratios performance on opposed piston 2-stroke engine
}

\begin{abstract}
Numerous skills involving the introduction of $(O P)$ opposed piston engine have been developed in the recent past. Indeed, novel techniques can help to improve the performance of the engine. The aim of this paper is to model and simulate a simple single-cylinder two-stroke opposed-piston engine and minimise fuel consumption and heat loss, using the software programme AVL BOOST ${ }^{\mathrm{m}}$. AVL BOOST is an engine modelling software, which analyses the performance of a modelled single cylinder two-stroke opposed-piston engine by changing desired parameters. In order to meet this aim, experimental results from a unique engine are used to make a comparison with the results obtained from AVL BOOST model. Six combinations of compression ratios (12, 13.5, 15, 16.5, 18 and 19.5) are analysed in this study with the engine speed running at $420 \mathrm{rpm}$ and $1500 \mathrm{rpm}$. In addition to the compression ratios, the effect of stroke-to-bore $(S / B)$ ratios on OP2S performance is investigated. Various values of $S / B$ ratios, whilst maintaining a constant swept volume, port geometry and combustion timing, and their effect on fuel consumption and heat loss are analysed in this study.

A comparison between the two engine speeds with increasing combinations of compression ratios, and the $S / B$ ratios revealed minimal differences in peak pressure, peak temperature, IMEP, ISFC, indicated efficiency and total heat loss. Detailed analyses of these parameters are highlighted in discrete sections of this paper.
\end{abstract}

Key words: opposed piston, AVL boost, VCR, compression ratio, numerical simulation

\section{Literature review}

Witting engineered the first $\mathrm{OP}$ engine to have appeared for public use in Germany, in 1878. Although, it was only commercialised for land marine and aviation purposes in the 1900s. Pinault and Flint [2], interpret that Witting's OP engine has a classic three-throw crank with the centre throw linked to the inner piston, which operated on a four-stroke cycle. Prolific OP engines have typically functioned on a two-stroke cycle, as they were prominent in achieving high thermal efficiency as well as high power density. In 1888, Oechelhaeuser and Hugo Junkers revolutionised OP engines with the consideration of two-stroke operation. This OP2S engine produced some immense figures with a mechanical efficiency of $77 \%$ and a $40 \%$ reduction in fuel consumption in comparison to a modern day four-stroke engine. Between 1930 and 1945, Hugo Junkers developed and manufactured OP engines for use in German civil and military airplanes. In World War Two, Junkers 205 and 207 aviation engines were record-breaking, in terms of fuel efficiency and reaching altitudes of 20,000 feet [3]. The basic concept, of Hugo Junkers, has employed in many applications with a trend towards very large capacity installations.

During the early 1900s, only a few OP engines were developed with a varying degree of success. One of which was the Doxford engines. William Doxford and Sons Ltd, was a British shipbuilding and marine engineering company. Doxfords developed vertical, OP2S diesel engines for ships (up to $8000 \mathrm{bhp}$ ). This design became a standard unit for British flag-carriers. However, in the early 1960s, the licence-built Sulzer and B\&W engines have been developed to overcome Doxfords pistons deficiencies. The single-crankshaft engines had connecting rods for both the lower and upper pistons, with two rods for the upper piston. The factor that differentiates Doxford's OP engine to
Junkers' OP engine is that in Doxford's the upper pistons are connected to the single crankshaft by connecting rods each side of the main cylinder. One of the advantages of Doxford's OP engines, over the traditional four-stroke engine, were that the two-stroke running enables a low operating speed $(115 \mathrm{rpm})$, which eliminates the requirement for a reduction gearbox between the engine and the propeller. In addition, no reverse gear was required since the engine was reversible. The Doxford engine was being predominant until its decline in 1980s. [4].

The Stelzer engine was proposed by Frank Stelzer. It uses conjoined pistons in a push-pull arrangement which allows for fewer moving parts and simplified manufacturing. Moreover, the engine fairly indestructible and almost maintenance-free. There are two combustion chambers and a central recompression chamber. Control of the air flow between the recompression chamber and the combustion chambers is made by stepped piston rods. In 1983, a prototype engine was demonstrated in Frankfurt. A prototype car with a Stelzer engine and electric transmission was shown at a German motor show in 1983 which thermodynamics efficiency of $56 \%$.

An exhaustive thermodynamic investigation has been practised by Herold et al. [5] titled; "Thermodynamic Benefits of Opposed-Piston Two-Stroke Engines" demonstrate the fundamental efficiency advantages of OP2S engine over a four-stroke engine with noticeable power output and geometry. From the simulation results, it can be observed that a $10.4 \%$ reduction was noted in ISFC over the four-stroke engine. Along with the geometric advantage of reduced heat transfer of OP architecture, the double firing frequency of the two-stroke cycle allows linear operating conditions. This enables the two-stroke cycle to maintain high ratio of specific heats during combustion, and reduced energy release density. The OP2S 
engine demonstrated an indicated thermal efficiency of $53 \%$, which is $5.5 \%$ greater than its four-stroke counterpart.

Another intriguing piece of work was carried out by Rishikesh Venugopal, in 2013; utilising three-dimensional (3D) computational fluid dynamics (CFD) integrated with state-of-the-art spray, turbulence and combustion models. Venugopal [6] analysed the effects of injection pattern design on piston thermal management through combined experiment and analytical approach.

Achates Power is based in San Diego, California and was founded in 2004 by James Lemke. At Achates Power, modern analytical tools, materials, and engineering methods have been enforced to develop an OP2S compression ignition engine for use in commercial and passenger vehicles. According to the Achates Power Opposed-Piston Two-Stroke Engine: Performance and Emissions Results in a Medium-Duty Application [1], "the engine design has demonstrated a $15-21 \%$ BSFC improvement compared to a state-of-the-art 2010 mediumduty diesel engine at similar engine-out emissions levels". Moreover, "oil consumption has been measured to be less than $0.1 \%$ of fuel over the majority of the operating range". With the two-stroke cycle, each combustion event is shorter in duration thus closer to optimum timing as compared to the four-stroke engines. While development of historic OP engines ceased for use in on-road car and truck applications with the introduction of modern emissions standards, Achates Power says that it has patented many modifications to the original architecture in order to meet current standards. A detailed numerical simulation of the Achates Power 1.64L single cylinder research engine is executed and validated against existing experimental data.

Most recently, WUT is developing a new-type barrel engine called PAMAR-4 under a Polish-Norwegian research programme. This is an iteration from a successor of PAMAR-3, which was a $3.0 \mathrm{~L}, 340 \mathrm{~kW}$ engine built for the purposes of aviation. PAMAR 3 was a huge success mainly due to an eight-cylinder barrel engine. Counterrotating cylinder groups and crankshaft provide cancellation of torque reactions and gyroscopic forces during engine speed fluctuations and vehicle manoeuvres. Some of the advantages of a barrel engine are as follows: simple technology; less parts required hence low weight; axial symmetry; low vibration level; and high power concentration. PAMAR-3 accomplished a test bench efficiency of $44 \%$ and has successfully functioned on LPG, propane, alcohol, CNG, gasoline and diesel fuels. One of the many reasons for the great outputs of the PAMAR-3 engine was due to an OP2S engine which meant; unnecessary strokes were eliminated; uniflow scavenging; and no valvetrain. In addition, the elimination of a crankshaft reduced piston side thrust. All of these factors led to an increased $\mathrm{ME}$, henceforth increased engine efficiency. Another reason for great outputs of the PAMAR-3 engine is due to its axial symmetry of cooling system - keeping a constant thermal condition in all cylinders - and inlet and exhaust axial symmetry - keeping a constant volumetric efficiency and equivalence ratio in all cylinders. Consequently, equal work of cylinders thus Homogeneous Charge Compression Ignition (HCCI) at whole range of loads. The manufacturing cost of PAMAR-3 engine was reduced by an incredible $40 \%$. Opaliński et al. [7] refers to a comparison of gas-dynamics of this engine, which has been modelled and quantified using Ricardo WAVE (1D) and Ansys Fluent (3D CFD).

\section{PAMAR engine}

A research team at WUT in Poland have been developing a modern car engine, called PAMAR, under the management of dr Pawel Mazuro. Having collaborated with the research team, some experimental data from PAMAR series engine were obtained and used for the modelling process of this project.

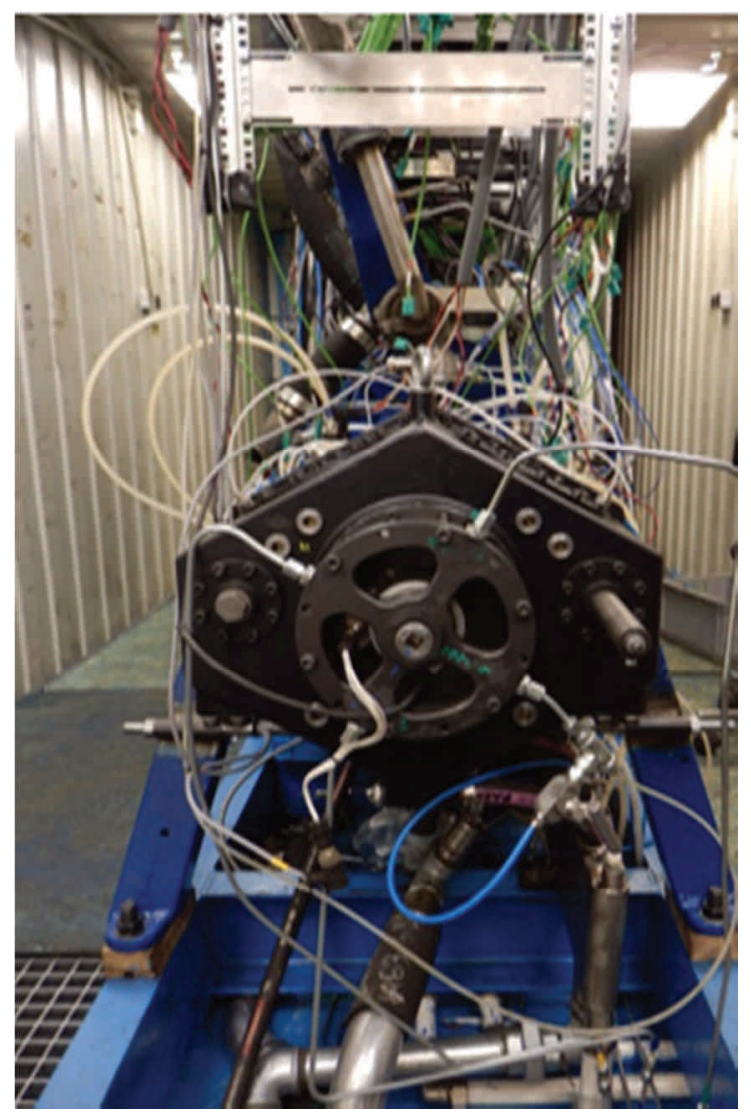

Fig. 1. PAMAR-4 Engine

\subsection{Numerical methodology}

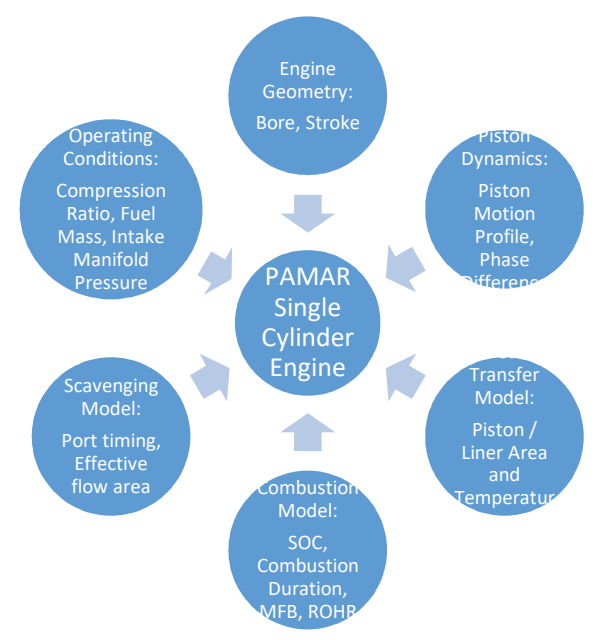




\subsection{PAMAR engine OP configuration}

PAMAR engine is equipped with uniflow scavenging system with an injector on its cylinder liner. Gas ports are positioned on either ends of the cylinder, intake ports to deliver fresh charge into the cylinder from one side, and exhaust ports on the other side to get rid of the burnt gas as well as residuals. The piston motion controls the opening and closing of these ports. Two pistons are deployed at opposite ends of the cylinder liner, intake and exhaust pistons, respective to their effective control of port opening and closing during the scavenging process. A combustion chamber is formed at inner dead center (IDC), i.e. at the point of minimum distance between the pistons. Outer dead center (ODC) is defined when the distance between two pistons are at maximum.

The reciprocation movements of piston are driven by opposed crank-connecting rod mechanism. The reciprocating movement accomplishes air-exchanging by combining the position with gas ports. [8]

\subsection{OP2S engine working cycle}

The OP2S cycle is completed by every crankshaft revolution. The compression stroke begins when the pistons entirely cover the intake and exhaust ports, and ends once the piston reaches IDC. At the end of the compression stroke, fuel is injected at high pressure, just before the pistons reach IDC. Subsequently, fuel is atomized, evaporated and burned in the high pressure, high temperature environment produced by the in-cylinder air which is then followed by the expansion stroke.

The expansion stroke is induced due to the prompt increase in pressure and temperature as a result of fuel combustion, causing the pistons to move from IDC to ODC. Near the end of the expansion stroke, exhaust ports are open to allow burnt gases to discharge with the aid of residual gas pressure. Moments later, the intake ports are opened, allowing the fresh charge to enter the cylinder at the same time driving the exhaust gas out of the cylinder. At this instant the in-cylinder pressure is lower than atmospheric pressure.

Scavenging process is vital as it comprises of both forcing the exhaust gas out of, and consenting fresh charge into, the cylinder. Intake and exhaust ports remain open at the start of the compression stroke, therefore scavenging process begins from the instant the ports are uncovered during the expansion stroke, and continues until completely closed again.

\section{Methodology}

\subsection{Numerical modelling of engines}

There are three major 1D engine simulation computer programs when it comes to numerical modelling of ICEs, namely GT POWER, Ricardo WAVE, and AVL BOOST ${ }^{\mathrm{T}}$. Unfortunately, since OP engines are unique, none of them has a built-in module capable of simulating an OP engine. Having said that, AVL BOOST is the favorite of the abovementioned, due to its compatibility of defining relative piston motion profile, thus enabling to model the OP configuration. In addition, AVL BOOST provides the option of advanced engine simulations in terms of cycle simulation, design and predictive combustion models, in comparison to other industrial modelling platforms.

\subsection{OP configuration in AVL BOOST}

As mentioned before, AVL BOOST has no built-in module capable of simulating an OP engine. Thus, simulating a flawless model of OP engine proved challenging at the initial stages of this project and some difficulties were encountered during the process of modelling.

\subsection{Engine cycle simulation}

The main tool used in AVL BOOST software is Workspace (graphical user interface), which is composed of predefined elements that represent components of ICE. The 1D engine model is built within the workspace by selecting various elements from the element tree and are joined by pipe attachments to their desired connectors. Table 1 lists all the elements, as well as quantity, used to create an OP configuration in AVL BOOST.

Table 1. Elements used to create an OP configuration in AVL BOOST

\begin{tabular}{|l|c|c|}
\hline \multicolumn{1}{|c|}{ Element } & Symbol & Quantity \\
\hline Engine & E & 1 \\
\hline Cylinder & C & 1 \\
\hline Plenum & PL & 2 \\
\hline Measuring Point & MP & 3 \\
\hline System Boundary & SB & 2 \\
\hline Pipe & - & 4 \\
\hline
\end{tabular}

Since an OP is an unique engine, a cylinder with a plenum on either side of the cylinder was modelled to create an OP configuration in AVL Boost. The screenshot of the model in AVL BOOST is represented in Figure 2.

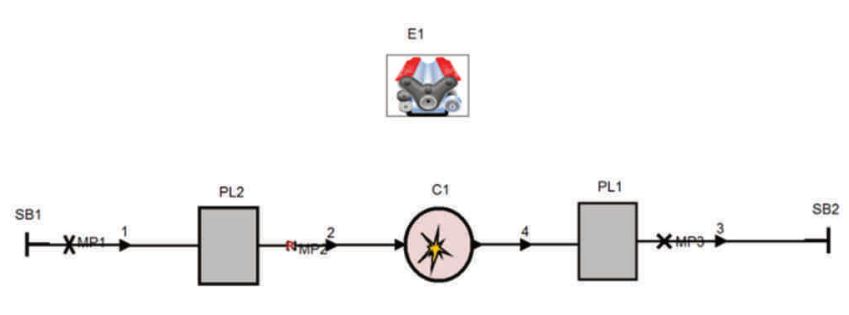

Fig. 2. Screenshot of the model in AVL Boost

\subsection{Defining constraints in AVL Boost}

Having designed the model in AVL BOOST, the data collected from PAMAR series engine were then entered into the computer software.

Certain constraints, such as crank radius, con-rod length, bore and stroke were collected from PAMAR. These values are listed in Table 2. Using these constraints, other parameters such as squareness, bore surface area and swept volume were calculated, which are also presented in Table 2. Although a piston stroke length of $150 \mathrm{~mm}$ was required, the con-rod length was defined as $300 \mathrm{~mm}$ (twice the stroke) in order for the software to assume it is an OP engine.

Phase difference was a vital variable in this investigation. It affects the minimum and maximum value of the cylinder volume. As the phase difference increases, the minimum distance between the pistons at IDC increases, thus reducing the maximum distance at ODC. Consequently, compression ratio is adversely affected. 
Table 2. Engine geometry parameters used in AVL BOOST

\begin{tabular}{|l|c|}
\hline \multicolumn{1}{|c|}{ Parameter } & Value \\
\hline Crank Radius (mm) & 75 \\
\hline Con-rod length (mm) & 300 \\
\hline Bore $(\mathrm{mm})$ & 55 \\
\hline Stroke $(\mathrm{mm})$ & 150 \\
\hline Squareness & 0.367 \\
\hline Bore Surface Area $(\mathrm{cm} 2)$ & 23.76 \\
\hline Swept Volume $(\mathrm{cm} 3)$ & 356 \\
\hline
\end{tabular}

According to $\mathrm{Ma}$ et al. [8], with increasing piston motion difference, from $0^{\circ}$ to $18^{\circ}$, delivery ratio and scavenging efficiency increases progressively throughout. On the other hand, trapping efficiency initially increases and then decreases after it achieves optimum efficiency at $15^{\circ}$, so does indicated work. As a result, $15^{\circ}$ was decided upon as phase difference. The intake port and exhaust port dimensions are listed in Table 3.

Table 3. Dimensions for intake port and exhaust port

\begin{tabular}{|l|c|c|}
\hline & Intake port & Exhaust port \\
\hline Height $(\mathrm{mm})$ & 20 & 25 \\
\hline Width $(\mathrm{mm})$ & 6.4 & 6.4 \\
\hline Number of holes & 24 & 18 \\
\hline $\begin{array}{l}\text { Maximum Flow Area } \\
(\mathrm{mm} 2)\end{array}$ & 3072 & 2880 \\
\hline Phase difference $\left({ }^{\circ}\right)$ & 0 & 15 \\
\hline
\end{tabular}

Since AVL BOOST has no built-in module capable of simulating an OP engine, the piston motion was user defined. Due to a phase difference in piston motion on both pistons, the two pistons are out of alignment, thus nonharmonic (i.e. do not reach IDC in harmony). Having decided upon a value for the phase difference $(\alpha)$, the piston displacements were calculated using the following equations [8]:

$$
\begin{aligned}
& X_{\text {in }}=r\left(1-\cos \left(\varphi-\frac{\alpha}{2}\right)+\frac{1}{2} \lambda \sin ^{2}\left(\varphi-\frac{\alpha}{2}\right)\right) \\
& X_{\text {ex }}=r\left(1-\cos \left(\varphi+\frac{\alpha}{2}\right)+\frac{1}{2} \lambda \sin ^{2}\left(\varphi+\frac{\alpha}{2}\right)\right)
\end{aligned}
$$

where: $X_{\mathrm{in}}$ and $\mathrm{X}_{\mathrm{ex}}$ are displacement of the intake and exhaust piston respectively; $r$ is the crank radius; $\lambda=r / 1$ is the ratio of crank radius to connecting rod; 1 is the length of the connecting rod; $\varphi$ is the equivalent crank angle.

Intake and exhaust pistons move towards each other face-to-face. One of the limitations observed whilst modelling an OP engine is that the option user defined piston motion in AVL BOOST only allows to input a relative position of the piston profile. Relative displacement is obtained by simply adding the displacements of each piston. This approach conserves the volume change rate of the engine, therefore avoiding possible discrepancies of work done in the thermodynamic cycle. The relative displacement of piston was determined by the following equation [8]:

$$
\mathrm{X}_{\text {relative }}=\mathrm{r}\left(1-\cos \left(\alpha-\frac{\varphi}{2}\right)\right)+\mathrm{r}\left(1-\cos \left(\alpha+\frac{\varphi}{2}\right)\right)
$$

From the graph above, it is evident that the compression and expansion stroke of this OP2S engine is asymmetric about the IDC. The exhaust piston leads from $0^{\circ} \mathrm{CA}$ to $180^{\circ} \mathrm{CA}$ and the intake piston leads from $180^{\circ} \mathrm{CA}$ to $360^{\circ} \mathrm{CA}$ relative to each other.

The effect of variable compression ratio on OP2S engine performance was analysed. To investigate this effect, six different values for the compression ratio were selected upon ranging from $12-20$. Using the compression ratios, clearance volume and clearance height were calculated which are presented in Table 4.

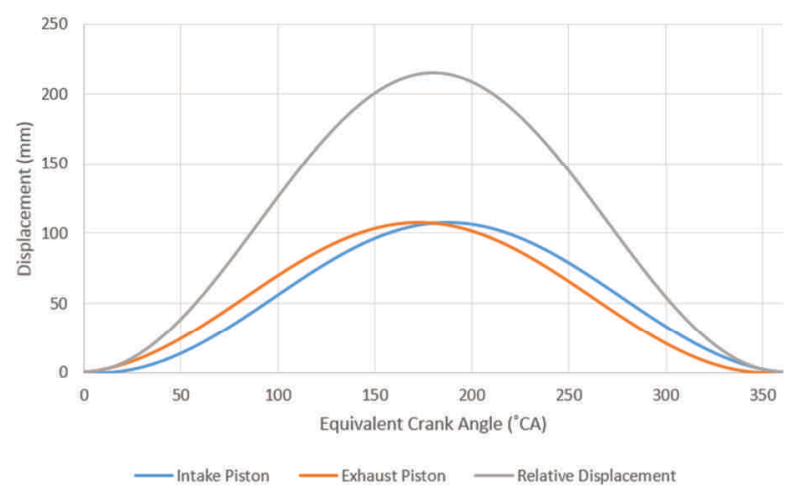

Fig. 3. Graph of piston motion profile

Table 4. Variables of the model

\begin{tabular}{|l|c|c|c|c|c|c|}
\hline Compression ratio & 12 & 13.5 & 15 & 16.5 & 18 & 19.5 \\
\hline $\begin{array}{l}\text { Clearance volume } \\
{\left[\mathrm{mm}^{3}\right]}\end{array}$ & 32398 & 28510 & 25455 & 22992 & 20963 & 19263 \\
\hline $\begin{array}{l}\text { Clearance height } \\
{[\mathrm{mm}]}\end{array}$ & 13.636 & 12 & 10.714 & 9.677 & 8.824 & 8.108 \\
\hline
\end{tabular}

The heat release rate was calculated in Microsoft Excel using pressure obtained from experimental data of PAMAR series engine, and volume using the parameters in Table 2. The pressure and volume were obtained for one cycle $\left(360^{\circ}\right)$ with an increment of $0.5^{\circ}$. Pressure and volume against crank angle degree (CAD) are illustrated in Figures $4 \mathrm{a}$ and $4 \mathrm{~b}$ respectively.

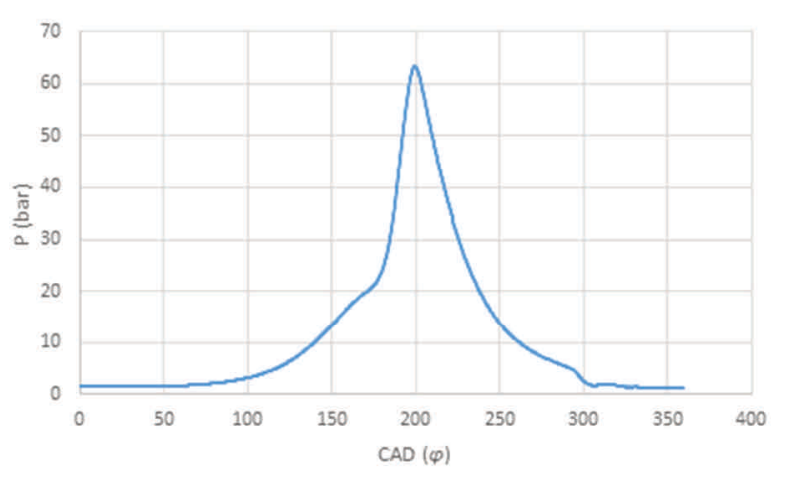

Fig. 4a. Graph of cylinder pressure against CAD

The change in cylinder volume with respect to CAD was calculated using Equation 4 from [9], where: A is bore area; $r$ is crank radius; $\varphi$ is crank angle; and $\lambda$ is ratio of crank radius to con-rod length. 


$$
\mathrm{V}=\operatorname{Ar}\left[(1-\cos \varphi)+\frac{\lambda}{4}(1-\cos 2 \varphi)\right]
$$

A $\mathrm{p}-\mathrm{V}$ diagram was plotted to visualise the changes in pressure with respect to volume in an opposed-piston system (see Fig. 4c). The graph also represents the amount of energy expended or received by the system as indicated work which can be determined by integrating the area within the curve.

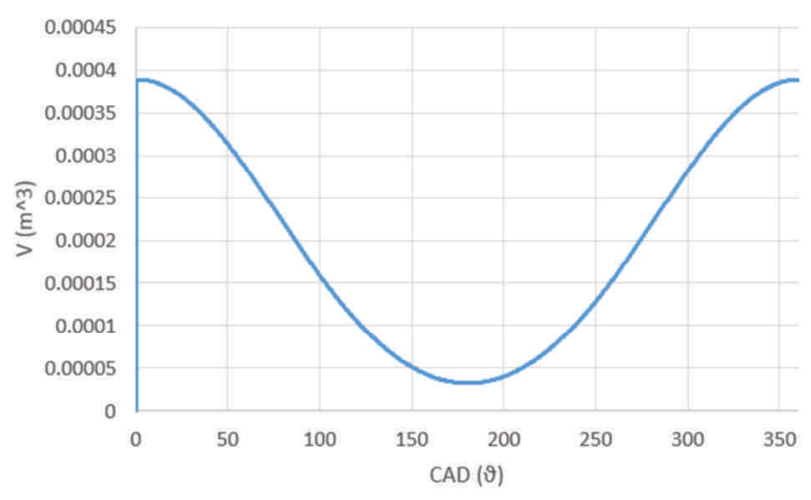

Fig. 4b. Graph of cylinder volume against CAD

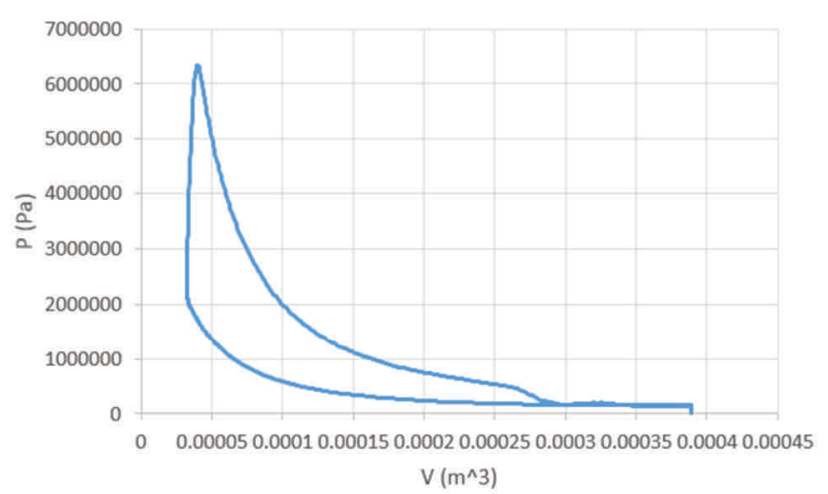

Fig. 4c. Graph of cylinder pressure against cylinder volume

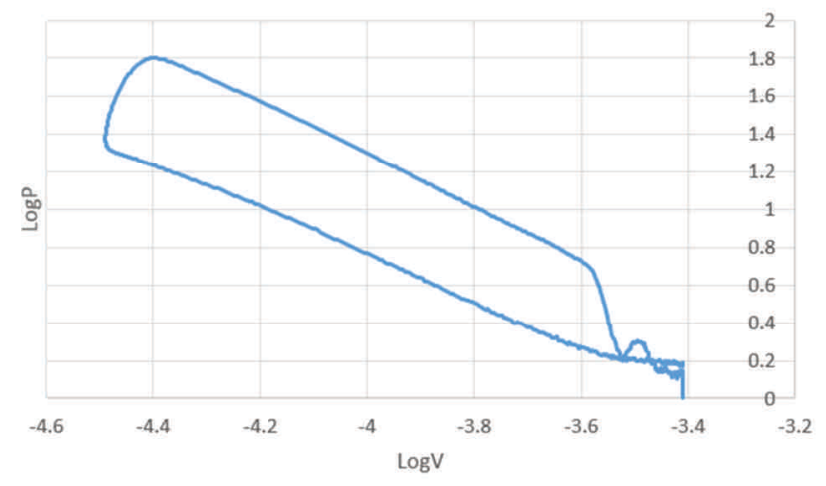

Fig. 4d. Graph of $\log \mathrm{P}$ against $\log \mathrm{V}$

Figures $4 \mathrm{c}$ and $4 \mathrm{~d}$ shows pressure-volume data on both a linear $\mathrm{p}-\mathrm{V}$ and a $\log (\mathrm{p})$ versus $\log (\mathrm{V})$ diagram. In Figure $4 \mathrm{~d}$, the compression process is a straight line of slope 1.32, and the expansion stroke following combustion is essentially linear with slope 1.36. Since both the compression of the unburned mixture prior to combustion and the expansion of the burned gases following the end of combustion are close to adiabatic isentropic process (for which $\mathrm{pV}^{\mathrm{k}}=$ constant; $\mathrm{k}=\mathrm{c}_{\mathrm{p}} / \mathrm{c}_{\mathrm{v}}$ ), the observed behaviour is as expected [10]. More extensive studies [11,12] show that the compression and expansion process are well fitted by a polytrophic relation:

$$
\mathrm{pV}^{\mathrm{n}}=\text { const }
$$

$\log (\mathrm{p})$ versus $\log (\mathrm{V})$ plots can be used to check the quality of cylinder pressure data [10]. Furthermore, $\log (\mathrm{p})$ versus $\log (\mathrm{V})$ plots approximately define the start and end of combustion, but do not provide a mass fraction burned profile.

Heat release calculations are an approach to acquire information about combustion processes. Heat release analysis is performed based on Cylinder Gas Pressure (CGP) data. The most widely used one was developed by Krieger and Borman [13].

Using the cylinder pressure (p), cylinder volume (V) and the obtained polytropic index $(\mathrm{k})$, the heat release rate (HRR) was calculated with using Equation 6 [14].

$$
\mathrm{HRR}=\frac{\mathrm{k}}{\mathrm{k}-1} \mathrm{p} \frac{\mathrm{dV}}{\mathrm{d} \varphi}+\frac{1}{\mathrm{k}-1} \mathrm{v} \frac{\mathrm{dP}}{\mathrm{d} \varphi}
$$

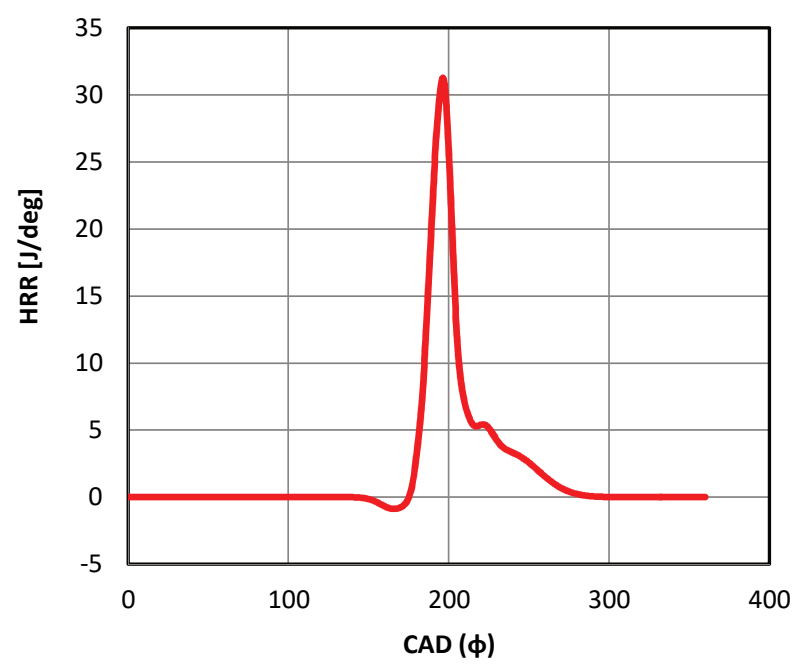

Fig. 5. Graph of heat release rate against CAD

The piston and cylinder head shapes and valve geometry influence the turbulence level in the engine and therefore the rate of heat release during combustion [15].

Having calculated the desired values and specified the range for compression ratio, the simulation was set to run at two engine speeds, $420 \mathrm{rpm}$ and $1500 \mathrm{rpm}$, to make a comparison. In these, the rate of heat release was assumed as not changing between cases.

\section{Effect of variable compression ratio (VCR)}

VCR is a technology that allows to adjust the compression ratio of an engine while it is in operation to increase fuel efficiency while under varying loads. Thus, a VCR mode allow for the volume passed the piston at IDC to be changed. For automotive use this is achieved dynamically in response to the load and driving demands. VCR is a cost-effective method of achieving increased fuel 
economy, reduced carbon dioxide emission about 30-40\% in comparison to conventional motors.

The effect of variable compression ratio at two different engine speeds - $420 \mathrm{rpm}$ (simulation 1) and $1500 \mathrm{rpm}$ (simulation 2) - was investigated and discussed in this section. To do so, the following parameters were analysed: IMEP; peak pressure; peak temperature; ISFC; BSFC; volumetric efficiency; and mechanical efficiency. The results obtained from AVL Boost are presented in a tabular form below.

Table 5. Results obtained from AVL Boost

\begin{tabular}{|c|c|c|c|c|c|c|c|c|c|c|c|c|}
\hline \multirow{2}{*}{ Parameters } & \multicolumn{6}{|c|}{ Compression Ratio } & \multicolumn{6}{|c|}{ Compression Ratio } \\
\hline & 12 & 13.5 & 15 & 16.5 & 18 & 19.5 & 12 & 13.5 & 15 & 16.5 & 18 & 19.5 \\
\hline Peak Pressure (MPa) & 5.02209 & 5.36196 & 5.67318 & 5.95697 & 6.21475 & 6.44725 & 5.10922 & 5.48479 & 5.81518 & 6.12601 & 6.41423 & 6.68478 \\
\hline Peak Temperature $(\mathrm{K})$ & 2490.22 & 2493.29 & 2496.08 & 2499.01 & 2500.41 & 2501.73 & 2560.58 & 2570.6 & 2576.03 & 2582.04 & 2585.18 & 2588.01 \\
\hline $\operatorname{IMEP}(\mathrm{Pa})$ & 784179 & 785847 & 785967 & 784786 & 782716 & 779981 & 926046 & 941214 & 951718 & 962099 & 969500 & 976128 \\
\hline BMEP (Pa) & 684179 & 685847 & 685967 & 684786 & 682716 & 678881 & 810046 & 825214 & 835718 & 846099 & 853500 & 860128 \\
\hline ISFC (kg/Ws) e-008 & 7.3713 & 7.3557 & 7.3546 & 7.3656 & 7.3851 & 7.4110 & 6.2421 & 6.1415 & 6.0737 & 6.0082 & 5.9623 & 5.9218 \\
\hline BSFC(kg/Ws) e-008 & 8.4487 & 8.4282 & 8.4267 & 8.4412 & 8.4668 & 8.5009 & 7.1359 & 7.0048 & 6.9167 & 6.8319 & 6.7726 & 6.7204 \\
\hline Indicated Efficiency & 0.311864 & 0.312527 & 0.312575 & 0.312105 & 0,311282 & 0.310194 & 0.368284 & 0.374316 & 0.378493 & 0.382622 & 0.385565 & 0.388201 \\
\hline \begin{tabular}{|l} 
Pressure @ @OC $(\mathrm{Pa})$ \\
\end{tabular} & 2.38144 & 2.67484 & 2.95111 & 3.22056 & 3.48481 & 3.73191 & 2.36844 & 2.66704 & 2.95881 & 3.24454 & 3.52245 & 3.79302 \\
\hline Temperature @SOC (K) & 903.942 & 927.435 & 948.214 & 966.715 & 983.771 & 997.751 & 898.031 & 928.395 & 945.961 & 966.209 & 984.407 & 1000.98 \\
\hline Vomuetric effciency & 0.880563 & 0.86811 & 0.857698 & 0.849614 & 0.842933 & 0.837365 & 0.855234 & 0.842658 & 0.832687 & 0.824669 & 0.818034 & 0.812466 \\
\hline Delivery ratio & 91.5004 & 91.5061 & 91.5108 & 91.5156 & 91.5208 & 91.526 & 26.6925 & 26.6928 & 26.6935 & 26.6939 & 26.6945 & 26.6949 \\
\hline Heat loss - Liner (kJ) & 0.105667 & 0.105763 & 0.105747 & 0.105758 & 0.105778 & 0.105768 & 0.0799471 & 0.0799402 & 0.0799343 & 0.0799293 & 0.0799251 & 0.0799215 \\
\hline Heat loss - Total (kJ) & 0.123945 & 0.12405 & 0.124032 & 0.124044 & 0.124066 & 0.124055 & 0.0940821 & 0.0940792 & 0.0940763 & 0.094074 & 0.0940719 & 0.0940707 \\
\hline Indicated Power (kW) & 1.96 & 1.96 & 1.96 & 1.96 & 1.96 & 1.96 & 8.25 & 8.39 & 8.48 & 8.57 & 8.64 & 8.7 \\
\hline Friction Power $(\mathrm{kW})$ & 0.25 & 0.25 & 0.25 & 0.25 & 0.25 & 0.25 & 1.03 & 1.03 & 1.03 & 1.03 & 1.03 & 1.03 \\
\hline Brake Power (kW) & 1.71 & 1.71 & 1.71 & 1.71 & 1.71 & 1.71 & 7.22 & 7.35 & 7.45 & 7.54 & 7.61 & 7.68 \\
\hline Indicated Thermal Efficie & & & & & & & & & & & & \\
\hline Mechanical Efficiency & 0.87244898 & 0.87244898 & 0.87244898 & 0.87244898 & 0.87244898 & 0.87244898 & 0.875151515 & 0.876042908 & 0.878537736 & 0.879813302 & 0.880787037 & 0.882758621 \\
\hline
\end{tabular}

Some parameters either remained constant with increasing CR or did not show a trend. This suggests that these parameters were independent of CR. Thus, Graphs of each parameter mentioned above against compression ratio were plotted for both simulations of the models to visualise values in Table 5 clearly.

\subsection{Indicated mean effective pressure (IMEP)}

IMEP is the ratio of indicated work to swept volume. IMEP is a fictitious constant pressure that would produce the same amount of work per cycle if it acted on the piston during the power stroke.

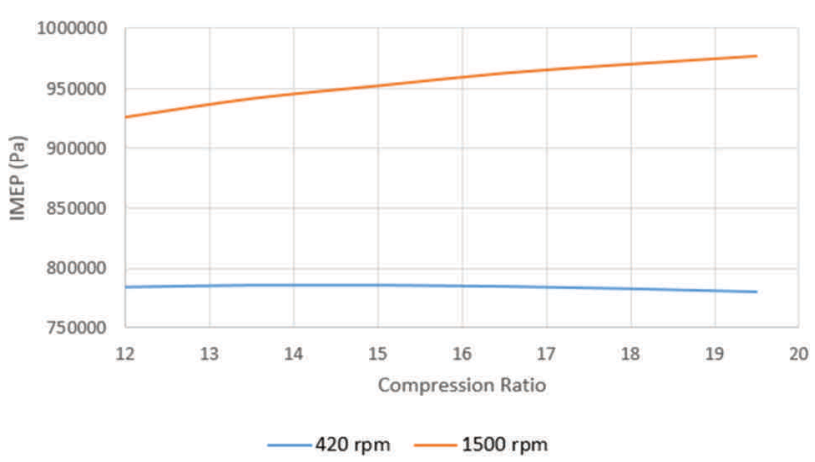

Fig. 6a. Graph of IMEP against compression ratio

The general trend is that a higher IMEP is achieved with increasing engine speed. In simulation 1, IMEP remains approximately around $780000 \mathrm{~Pa}$ where as in simulation 2, when the engine speed was increased from $420 \mathrm{rpm}$ to 1500 rpm, IMEP starts to increase from $926046 \mathrm{~Pa}$ to $976128 \mathrm{~Pa}$, with increasing CR. The IMEP is higher when the engine speed is set at $1500 \mathrm{rpm}$.

\subsection{Peak pressure}

The purpose of an engine is to generate internal pressure which can be used to do work. Therefore, high pressures are desirable. However, excessively high and erratic pressures are a source of potential damage and should be avoided.

Cylinder pressure is the pressure in the engine cylinder during the two strokes of engine operation. Cylinder pressure is constantly changing inside the cylinder for both strokes. There are certain characteristics of this pressure which can be analysed, for example peak (maximum) cylinder pressure near IDC.

During the combustion stroke, the air/fuel mixture is ignited, creating very high cylinder pressure which rise very quickly (also known as the peak pressure). This is where the engine's power comes from, as it forces the piston down. As the piston moves towards ODC, the cylinder volume increases which reduces the cylinder pressure. When the piston reaches ODC there will be a significant amount of reduction in cylinder pressure.

Peak pressures occurring during combustion are much higher and are more difficult to obtain by calculation. Thus, AVL BOOST was used to determine the peak pressure for each case. Figure $6 \mathrm{c}$ indicates the change in peak pressure with increasing $\mathrm{CR}$.

For the $420 \mathrm{rpm}$ simulation, at a compression ratio of 12 and 19.5 the peak pressures were 5.02 $\mathrm{MPa}$ and 6.45 $\mathrm{MPa}$, 
respectively. As for the $1500 \mathrm{rpm}$ simulation, at a compression ratio of 12 and 19.5 the peak pressures were 5.11 MPa and 6.68 MPa, respectively.

The general trend is that peak pressure increases with increasing $\mathrm{CR}$. Since, compression ratio is equal to the ratio of volume at ODC and volume at IDC, compression ratio is inversely proportional to the volume at IDC. Thus, a higher $\mathrm{CR}$ means a reduction in volume at IDC. A reduction in volume at IDC means that the piston can do more work and compress the air/fuel ratio further, hence increasing the cylinder pressure at IDC (i.e. peak pressure). Thus, an increase in $\mathrm{CR}$ means an increase in peak pressure.

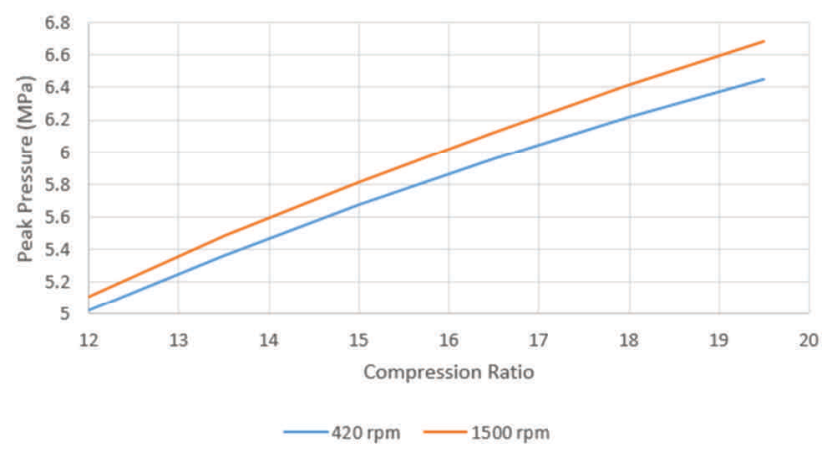

Fig. 6b. Graph of peak pressure against compression ratio

A more observed trend that can be obtained from Figure $6 \mathrm{~b}$ is that a higher engine speed results in a higher peak pressure. At $420 \mathrm{rpm}$ and $1500 \mathrm{rpm}$, the maximum peak pressure obtained were $6.45 \mathrm{MPa}$ and $6.68 \mathrm{MPa}$ (at a CR of 19.5), respectively. As the engine speed increases, the mixture in the combustion chamber must be ignited earlier as there is less time between spark and optimum peak pressure angle. In case the mixture density is changed due to higher compression ratio or boost, the spark has to be ignited later to achieve the same optimal point.

\subsection{Peak temperature}

During the combustion process, the cylinder gas temperature reaches a high value (known as the peak temperature). The maximum temperature was recorded at the IDC. A considerable amount of heat is transferred to the walls of the combustion chamber. Thus, it is vital to provide proper cooling to the walls of the combustion chamber. Chemical and physical changes in the lubricating oil are possible to occur due to the prevailing high temperature. Excessive cylinder wall temperatures will therefore cause the rise in the operating temperature of piston head, which can affect the strength of the piston severely.

Figure 6c suggests that for both simulations peak temperature increases with increasing $\mathrm{CR}$. At an engine speed of $420 \mathrm{rpm}$ peak temperature increases from 2490.22 $\mathrm{K}$ to $2501.73 \mathrm{~K}$, and when the engine speed was set at 1500 rpm peak temperature increases from $2560.58 \mathrm{~K}$ to 2588.01 $\mathrm{K}$. This suggests that at low engine speed, peak temperature increases with very small increments as the CR increases.

According to [15]: 'Peak temperatures may range from 2400 to $2800 \mathrm{~K}$ '. Thus, the peak temperatures obtained from AVL BOOST are acceptable.

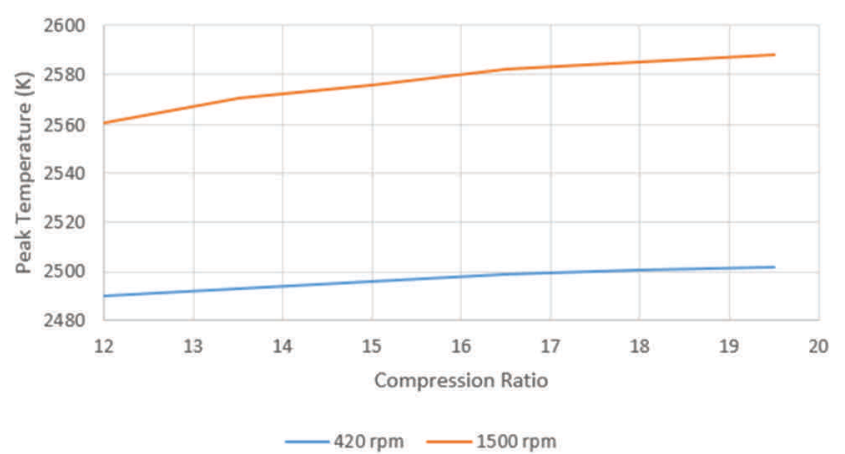

Fig. 6c. Graph of peak temperature against compression ratio

The compression due to piston motion and combustion in a confined volume leads to very high burned gas temperatures in reciprocating engines. The compression ratio determines the peak pressure and hence the peak temperature in the cycle. An increase in $\mathrm{CR}$ reduces clearance volume at IDC. As a result, cylinder pressure increases as it compresses air/fuel mixture further. Work done by the gas in the cylinder on the piston during the compression stroke heats the combustion products, thus increasing cylinder gas temperature. Therefore, increasing the $\mathrm{CR}$, increases peak temperature.

Nitrogen oxides $\left(\mathrm{NO}_{\mathrm{x}}\right)$ emissions result from the thermal fixation of atmospheric nitrogen, so control of these emissions can be achieved by reducing the peak flame temperatures. Therefore, in order to reduce lower peak temperature, the compression ratio must also be lower, thereby limiting $\mathrm{NO}_{\mathrm{x}}$ formation. On the other hand, the $\mathrm{NO}_{\mathrm{x}}$, emission reductions achieved by reducing $\mathrm{CR}$ are smaller in comparison to those accumulated by retarding the spark. One other way of reducing peak temperature is by diluting the charge with cool combustion products. This process is known as exhaust gas recirculation (EGR). The benefits of cooling combustion products for dilution instead of excess air are as follows: 1) dilution of the air/fuel mixture without the addition of excess $\mathrm{O}_{2}$ that aids in $\mathrm{NO}_{\mathrm{x}}$ formation; and 2) an increase in the specific heat of the gas due to the presence of $\mathrm{H}_{2} \mathrm{O}$ and $\mathrm{CO}_{2}$, reducing the temperature somewhat more than would equivalent dilution with excess air. Another way of reducing peak temperature is through exhaust gas recirculation or retarding the injection timing. Injection timing delays cause the heat release to occur late in the cycle, after some expansion work has occurred, thereby lowering the peak temperature.

\subsection{Engine efficiency}

Engine efficiency is becoming a more prominent factor in automobile manufacturer's decision making. It is the relationship between the total energy contained in the fuel, and the amount of energy used to perform useful work. This makes engine efficiency one of the most vital factors to consider when modelling an internal combustion engine. Three efficiencies were discussed in this section of the report and these were: indicated, volumetric and mechanical. 


\subsubsection{Indicated efficiency}

Thermal efficiency can be quoted as either brake or indicated. Indicated efficiency is derived from measurements taken at the flywheel.

Indicated efficiency is calculated as a result of indicated power. Since the indicated powers for the $420 \mathrm{rpm}$ and $1500 \mathrm{rpm}$ simulations remain constant (at 31\%) and increase in small increments (from $36.8 \%$ to $38.8 \%$ ) respectively, a similar observation can be noted for the indicated efficiencies also. Like the indicated power, the indicated efficiency is also higher when the engine speed is set at $1500 \mathrm{rpm}$, implying the power developed by combustion of fuel in the engine cylinder is greater with increased engine speed. This can be validated with the following equation

$$
\mathrm{ip}=\mathrm{P} \cdot \mathrm{V} \cdot \mathrm{N} \cdot \mathrm{K}
$$

where: ip is the indicated power; $\mathrm{P}$ is the mean pressure; $\mathrm{V}$ is the displacement volume; $\mathrm{N}$ is the rotational speed; and $\mathrm{K}$ is the number of cylinders.

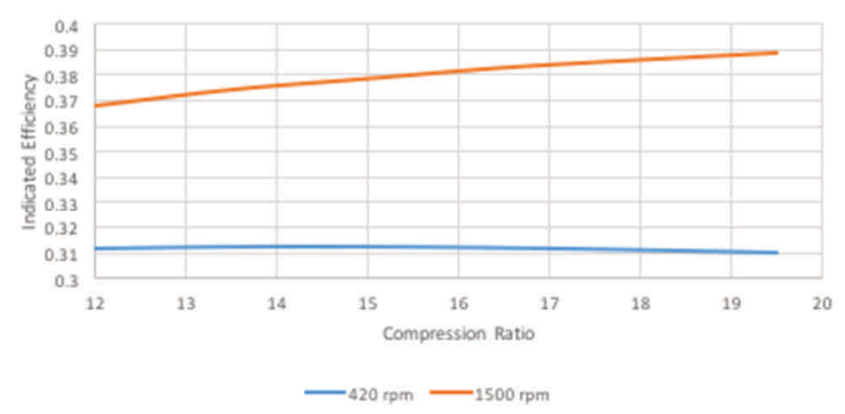

Fig. 6d: Graph of indicated efficiency against compression ratio

Thus, from Equation 7, indicated power is directly proportional to the rotational speed (i.e. engine speed).

\subsubsection{Volumetric efficiency}

The volumetric efficiency is probably one of the most variable efficiencies governing the performance of engines. Volumetric efficiency is the ratio of the actual volume of the air/fuel mixture drawn in during combustion to the swept volume of the piston. Volumetric efficiency determines how efficiently fuel is burnt thus affecting the power output, because the amount of air drawn inside the cylinder is dependent on the volumetric efficiency of an engine.

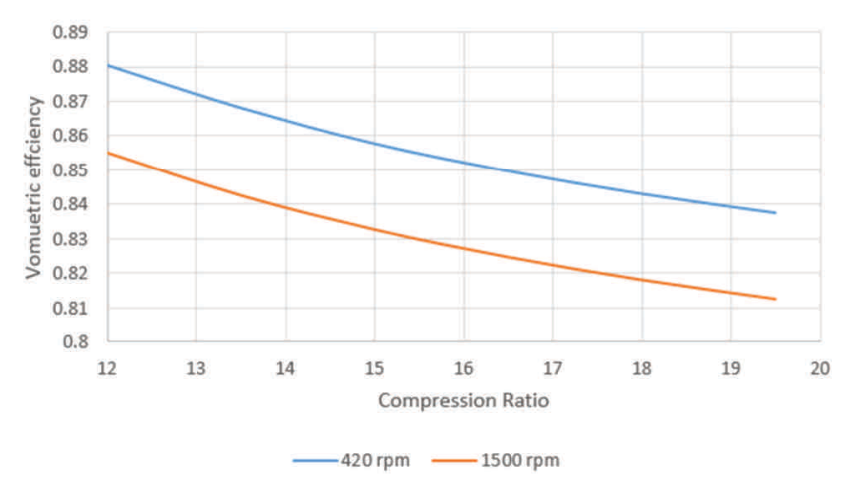

Fig. 6e. Graph of volumetric efficiency against compression ratio
The general trend is that volumetric efficiency decreases with increasing CR. When the engine speed was set at 420 $\mathrm{rpm}$, the volumetric efficiency reduced from $88.1 \%$ to $83.7 \%$. Similarly, the volumetric efficiency reduced from $85.5 \%$ to $81.2 \%$, when the engine speed was set at 1500 rpm.

Typical values for WOT are in the range $75 \%-90 \%$, and lower when the throttle is closed [16]. For both simulations, volumetric efficiency is within the typical range, thus the values obtained from AVL Boost are acceptable.

$$
\mathrm{CR}=\frac{\mathrm{Vs}+\mathrm{Vc}}{\mathrm{Vc}}
$$

where: Vs is swept volume; and Vc is clearance volume.

$$
\eta \mathrm{v}=\frac{\mathrm{Vair}}{\mathrm{Vs}}
$$

where: $\eta v$ is volumetric efficiency; and Vair is volume of air drawn into cylinder.

Therefore, equating Equations 8 and 9 gives:

$$
\mathrm{Vs}=\frac{\mathrm{Vair}}{\eta \mathrm{v}}=(\mathrm{CR} * \mathrm{Vc})-\mathrm{Vc}
$$

Compression ratio is inversely proportional to volumetric efficiency, thus results obtained from AVL Boost are acceptable.

The value of volumetric efficiency of a normal engine lies between 70 and $80 \%$ [16], and the values obtained from AVL Boost lies between 80 and 90 percent, proving an OP engine is volumetrically more efficient in burning fuel.

One way of increasing the engine volumetric efficiency in order to increase engine power would be forced induction. This can be achieved by using turbo or supercharger. This draws in more air into the cylinder thus increasing volumetric efficiency.

Another method of increasing volumetric efficiency is induction ram. However, this only occurs at high speed and is due to the inertia of the high-speed air. In part intake valves are left open after ODC to take advantage of this.

A third way of improving volumetric efficiency is intake tuning. The reflected pressure waves can be used to increase the air density at the inlet valve just prior to closing. This method is key to the success of naturally aspirated engines.

\subsubsection{Mechanical Efficiency}

The mechanical efficiency is how much of the power developed by the expanding of the gases in the cylinders is actually delivered as useful power.

Some of the power generated in the cylinder is used to overcome engine friction. The friction power (i.e. the power loss in the mechanical components of engine due to friction) is defined as the difference between the indicated power and brake power (i.e. difference between the moving parts and the energy taken to run the auxiliary equipment such as the fuel pump, water pump, oil pump and alternator). Thus, the mechanical efficiency is defined as the ratio of brake power to indicated power.

Friction losses in the engine come from friction between moving parts (such as the piston rings on the cylinder walls), the power required to run the valve gear and the pumps, and the pumping losses involved in getting the 
gases in and out of the cylinder. A large part of the work appears as heat in the coolant and oil. The approximate breakdown of the contributions of each of the losses are as follows: pistons, rings, pins and rods $(46 \%)$; valve train (23\%); water pump and alternator $(13 \%)$; crankshaft and seals $(12 \%)$; and oil pump $(6 \%)$.

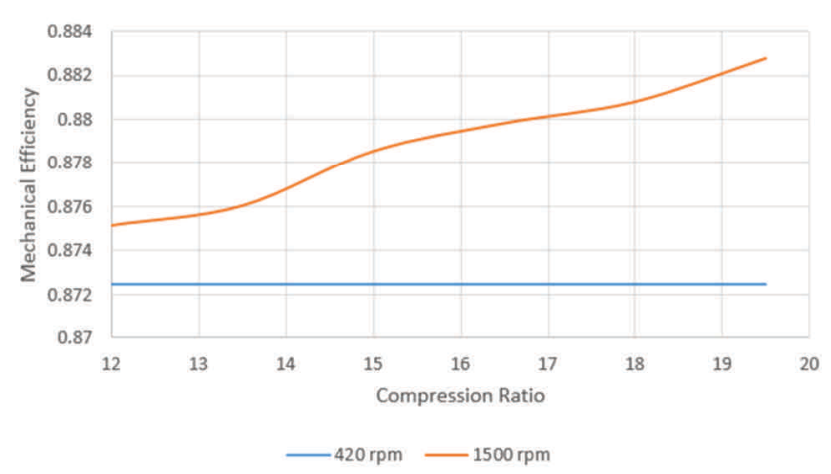

Fig. 6f. Graph of mechanical efficiency against compression ratio

For the $420 \mathrm{rpm}$ simulation, an indicated power of 1.96 $\mathrm{kW}$ and a brake power of $1.71 \mathrm{~kW}$ were obtained, thus a mechanical power of $87.2 \%$ was obtained from AVL Boost for each CR. This suggests that at low engine speed the mechanical efficiency is independent of compression ratio.

Conversely, once the engine speed was set at $1500 \mathrm{rpm}$, the mechanical efficiency increases with respect to compression ratio, as do the indicated power and brake power. Therefore, a higher engine speed has an effect on mechanical efficiency.

\section{Conclusion}

This report discussed the effect of variable compression ratio on OP2S engine performance by modelling and simulating a simple single-cylinder two-stroke opposedpiston engine in AVL Boost. The aim was achieved by completing all the objectives. Results obtained from AVL Boost indicate a general trend between the analysed parameters and compression ratio.

In conclusion, the analysis of the results showed that some parameters, such as IMEP, peak pressure, peak temperature and volumetric efficiency, have an effect when increasing the compression ratio. Positive correlations were attained when analysing IMEP, peak pressure and peak temperature. On the other hand, volumetric efficiency decreased with increasing compression ratio.

In addition, certain parameters, such as mechanical efficiency, were only affected when the engine speed was set at $1500 \mathrm{rpm}$, and remained constant at an engine speed of $420 \mathrm{rpm}$. One of the reasons as to why the results remained constant or had very little effect when increasing the compression ratio for simulation 1 is because perhaps $420 \mathrm{rpm}$ was too low of an engine speed to analyse engine performance. In future, a higher value of engine speed will be used and more simulations will be carried out to make a better comparison.

Finally, it is recommended to use AVL Boost to model and simulate an OP2S engine as it is easy and fast to setup model, and provide reliable and accurate simulation of steady and transient engine performance parameter.

\section{Nomenclature}

OP2S opposed-piston two-stroke

OP opposed-piston

CR compression ratio

IMEP indicated mean effective pressure

HCCI homogeneous charge compression ignition

IDC inner dead centre

ODC outer dead centre
ICE internal combustion engines

CAD crank angle degree

VCR variable compression ratio

BMEP brake mean effective pressure

FMEP friction mean effective pressure

SFC specific fuel consumption

\section{Bibliography}

[1] REGNER, G., HEROLD, R., WAHL, M. et al. The Achates power opposed-piston two-stroke engine: performance and emissions results in a medium-duty application. SAE Int. J. Engines. 2011, 4(3), 2726-2735.

[2] PIRAULT, J.-P., FLINT, M. Opposed piston engines: evolution, use, and future applications. SAE International. Warrendale, 2009.

[3] Achates. A Historical Look at Opposed-Piston Engines. 2011. (online) Available at: achatespower.com/opposedpiston-engine-history (accessed 19.10.2016).

[4] Tank and AFV News. Ukraine announces 1500 HP version of 6TD engine. 2016. (online) Available at: tankandafvnews.com/2016/05/24/ukraine-announces-1500hpversion-of-6td-engine (accessed 20.10.2016).

[5] HEROLD, R., WAHL, M., REGNER, G. et al. Thermodynamic benefits of opposed-piston two-stroke engines. SAE Technical Paper. 2011, 2011-01-2216.
[6] VENUGOPAL, R., ABANI, N., MACKENZIE, R. Effects of injection pattern design on piston thermal management in an opposed-piston two-stroke engine. SAE Technical Paper. 2013, 2013-01-2423.

[7] OPALIŃSKI, M., MAZURO, P., WYSZYNSKI, M. Comparison of flow performance in one and three dimensional software for modelling of opposed piston engines. Archivum Combustions. 2015, 35(1).

[8] MA, F., ZHAO, C., ZHANG, F. et al. An experimental investigation on the combustion and heat release characteristics of an opposed-piston folded-cranktrain diesel engine. Energies. 2015, 8(7), 6365-6381.

[9] XU, H.M. Powertrain lectures: engine operating dynamics. University of Birmingham. 2017.

[10] HEYWOOD, J.B. Internal combustion engine fundamentals. McGraw-Hill, 1988.

[11] LANCASTER, D.R, KREIGER, R.B., LIENESCH, J.H. Measurement and analysis of engine pressure data. SAE Technical Paper. 1975, 750026. 
[12] CARIS, D.F., NELSON, E.E. A new look at high compression engines. SAE Trans. 1959, 67, 112-124.

[13] KRIEGER, R.B., BORMAN, G.L. The computation of applied heat release for internal combustion engines. ASME Paper 66-WA/DGP-4; SAE Warrendale. 1966.

[14] BRUNT, M.F.J., RAI, H., EMTAGE, A.L. The calculation of heat release energy from engine cylinder pressure data. SAE Technical Paper. 1998, 981052.

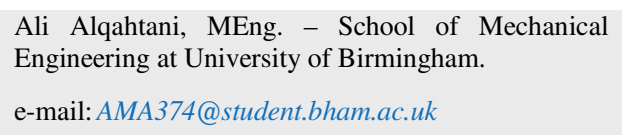

Paweł Mazuro, DEng. - Faculty of Power and Aeronautical Engineering at Warsaw University of Technology.

e-mail:Pawel.Mazuro@itc.pw.edu.pl
[15] FLAGAN, R.C. Internal combustion engines. 4th ed. 1988, 242, 248, 252, 274.

[16] RAJPUT, R.K. A text book of automobile engineering Google Books. Books.google.co.in. 2007-01-01. (accessed 9.03.2017).

Miroslaw L. Wyszynski,, MEng, PhD, MIDGTE, MSAE, MSIMP - Faculty of Mechanical Engineering at University of Birmingham.

e-mail:M.L.Wyszynski@bham.ac.uk

Hongming Xu, BEng, MEng, PhD, DIC, FSAE, CEng, FIMechE, FHEA - School of Mechanical Engineering at the University of Birmingham, UK

e-mail:H.M.Xu@bham.ac.uk
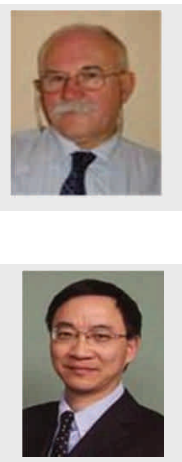